\title{
Contributions of Related Variables to Reading Comprehension in School-Age Children: A Two-Year Longitudinal Study
}

\author{
Bhu Ja Chung, Hyojin Yoon \\ Department of Speech-Language Pathology, Chosun University, Gwangju, Korea
}

Correspondence: Hyojin Yoon, $\mathrm{PhD}$ Department of Speech-Language Pathology, Chosun University, 309 Pilmun-daero, Dong-gu, Gwangju 61452, Korea

Tel: $+82-62-230-7462$

Fax: +82-62-230-6271

E-mail: hyoon@chosun.ac.kr

Received: July 5, 2019

Revised: August 1, 2019

Accepted: August 1, 2019

This work was supported by research fund from Chosun University, 2017.

\begin{abstract}
Objectives: Reading comprehension is a complex cognitive process consisting of various constructs. This 2-year longitudinal study explores the predictor variables on reading comprehension. Specifically, as criterion variables, two widely used reading comprehension tests, in open-ended format and cloze task format, were used to figure out different patterns of relations. Methods: Thirty-two typically developing children followed from early grades (1st and 2nd grades) to intermediate grades (3rd and 4th grades) completed measures of two formats of reading comprehension, word recognition, vocabulary, reading fluency, and morphological awareness. Correlations analyses and stepwise multiple regression analyses were undertaken. Results: The results showed that reading comprehension in the early grades contributed significantly to the same variables in the intermediate grades. Additionally, morphological awareness in the early grades accounted for unique variance in later open-ended reading comprehension. Word recognition and vocabulary in the early grades predicted later reading comprehension scores in cloze task format. The findings also suggested that reading fluency accounted for significant variance in reading comprehension during the same periods but not across the periods. Conclusion: The results of this study were consistent with previous studies that suggested the contributions of morphological awareness and reading fluency to reading comprehension. Findings also indicated that reading fluency might be a distinct variable along with word recognition and vocabulary.
\end{abstract}

Keywords: Longitudinal study, Reading comprehension, Word recognition, Reading fluency, Morphological awareness
읽기는 높은 수준의 지적 능력이 요구되는 복잡한 정신적인 과 정이며, 사고, 판단, 상상, 추론, 문제해결과 같은 다양한 영역이 관 여하기에(Catts \& Kamhi, 2005) 문자 상징을 해독하는 기술만으로 완성되지 않는다. 특히 읽기이해(reading comprehension)는 단어 를 해독하는 기술과 구문에 대한 이해력을 바탕으로 문장이나 글 의 의미를 처리하고 내용을 파악하는 능력으로 수년에 걸쳐 습득 되고 성숙되는 정신적인 과정이다. 따라서 지난 수십 년간 국내외 연구들은 읽기이해를 구성하고 예측하는 다양한 요인들을 탐색하 였고 이를 설명하는 모델을 발전시켜왔다(Cain, Oakhill, \& Bryant, 2004; Hoover \& Gough, 1990; Perfetti \& Hart, 2001).
일례로 읽기에 대한 단순 관점(simple view of reading) 모델은 단 어재인(word recognition)과 듣기이해(listening comprehension)를 읽기이해에 필수적인 그러나 독립적인 두 구성요소로 설명하였다 (Hoover \& Gough, 1990). 해독을 포함한 단어재인은 단어의 음운 적 코드를 정확하고 빠르게 인지하고 적용하는 능력을 의미하므로 읽기의 초기발달에서 핵심적인 과정으로 대부분의 초기연구들이 중점을 두는 변인이었다(Perfetti \& Hogaboam; Stanovich \& Siegel, 1994). 하지만 단어재인이 읽기이해에 미치는 예측력의 크기가 학년이 증가할수록 줄어들고(Cain et al., 2004), 오히려 자동화된 해독에 기반한 읽기유창성, 추론이나 어휘력 등의 언어능력 및 구 
문지식의 설명력이 점차 커지는 것으로 밝혀지면서(Storch \& Whitehurst, 2002; Verhoeven \& Van Leeuwe, 2008) 학년에 따라 변화하는 변인의 설명력에 대한 연구가 꾸준히 진행되었다.

Storch와 Whitehurst (2002)는 읽기발달의 예측변인들을 음운 인식, 인쇄물 지식, 쓰기전 기술과 같은 부호적 기술과 표현 및 수용 어휘, 내러티브 회상이나 개념지식과 같은 언어적 기술로 개념화하 여 학년에 따른 패턴을 분석하였는데, 그 결과 선행연구들과 마찬 가지로 저학년 시기에 강한 영향력을 보이던 부호적 기술들이 3학 년 이후부터 약화되고 언어적 기술이 읽기학습 과정에 영향을 미 치는 강력한 요인인 것으로 나타났다. 국내 연구들에서도 고학년이 되면 더 이상 단어해독이 주요한 설명력이 아니며 구문지식, 듣기이 해, 어휘와 같은 언어적 요소가 주요 변인인 것으로 드러났다(Kim, 2013; Kim, Yoo, Hwang, Kim, \& Koh, 2010; Yoon, 2015). 또한 최근 연구자들은 단어재인과 어휘뿐 아니라 읽기유창성(reading fluency)과 읽기이해의 유의한 관련성에도 주목하였는데(Fuchs, Fuchs, Hosp, \& Jenkins, 2001; Kim, Petscher, Schatschneider, \& Foorman, 2010), Kim, Kim과 Kang (2016)도 5세부터 초등 6학년 학생을 대 상으로 확인적 요인분석을 실시하여 본격적으로 읽기가 발달하는 초등학생의 경우 단어재인, 읽기유창성, 읽기이해가 별개의 요인임 을 보고하였다. Kim, Petscher 등(2010)의 연구에서도 1학년에서 3 학년에 이르는 종단연구 결과 3 학년의 읽기이해와 가장 강력한 관 련성을 지닌 변인이 저학년 시기의 읽기유창성으로 나타났다.

더욱이 최근에는 학년에 따라 증가하는 메타언어능력이 읽기이 해와 갖는 관련성도 강조되고 있다(Deacon, Kieffer, \& Laroche, 2014; Tong, Deacon, Kirby, Cain, \& Parrila, 2011). 메타언어능력이 란 말소리뿐 아니라 단어, 구, 문장의 의미를 조작하거나 해석하는 능력을 의미하는데, 그중 형태인식(morphological awareness)은 단 어 내 형태소의 구조를 인지하고 의식적으로 조작함으로써 형태론 적으로 복잡한 낮선 단어의 의미를 파악하거나 새로운 단어를 형 성해내는 능력을 일컫는다(Carlisle, 1995). Tong 등(2011)은 아동 집단을 읽기이해능력에 따라 분류하여 3 학년에서 5 학년에 이르는 종단연구를 진행하였고 읽기이해와 형태인식능력 간의 꾸준하고 유의한 관련성을 보고하였다. Deacon 등(2014) 또한 초등 3학년과 4 학년에 걸친 종단연구를 통해 형태인식이 읽기이해에 영향을 미 치는 주요 변인임을 밝혀냈다. 국내외 연구들은 꾸준히 형태인식이 그 특성상 어휘습득을 촉진함으로써 읽기이해에 직간접적으로 관 여하며(Bowers \& Kirby, 2010; Sparks \& Deacon, 2015), 형태인식 의 영향력 또한 어휘력과 마찬가지로 학년에 따라 증가한다고 보고 하고 있다(Chung, 2016; Deacon \& Kirby, 2004; Nagy, Berninger, \& Abbott, 2006). 이러한 연구결과들은 단어재인과 듣기이해에 국한
된 읽기의 단순관점 모델만으로는 읽기이해를 구성하는 다양한 변 인들을 예측하기 어려움을 함의하며, 읽기유창성이나 형태인식 등 의 다양한 변인을 함께 고려해야 할 필요성을 드러낸다.

또한 읽기이해는 다양한 변인들이 상호적으로 관련된 복잡한 인 지적 과정이기 때문에(Perfetti, Landi, \& Oakhill, 2005), 읽기이해 및 관련 영역을 측정하는 검사도구의 문항내용이나 유형에 따라 변인들이 보이는 예측력의 추이에 차이를 보이기도 하므로(Chung, Kim, \& Yoon, 2017; Cutting \& Scarborough, 2006; Keenan, Betjemann, \& Olson, 2008) 이에 관한 고려도 필요하다. 일례로 Chung 등(2017)은 초등 중학년을 대상으로 문답과제와 빈칸채우기와 같 은 두 가지 다른 형식의 읽기이해검사에 대한 예측변인을 탐색하였 다. 그 결과 어휘력이 두 형식의 읽기이해검사에서 공통적으로 주 된 설명력을 보였으나, 각각 형태인식과 음운기억 변인이 별도의 추 가적인 예측력을 보인 것으로 보고하였다. 이에 연구자들은 한국 어와 같은 표층표기체계 언어권의 경우 단어재인보다는 읽기유창 성이 지니는 예측력의 크기가 더 클 수 있으므로 향후 해당 변인을 고려한 연구를 제언한 바 있다.

읽기이해능력의 예측 변인을 탐색하는 종단연구방식은 동일한 아동을 대상으로 그 추이를 살펴볼 수 있다는 점에서 뚜렷한 장점 과 예측력을 지닌다. 앞서 언급한 국외연구들은 대부분 종단연구 방식을 통해 진행되었기 때문에 시간에 따라 변화하는 이해능력에 대한 조기의 예측변인들을 파악함으로써 인과관계에 대한 타당한 설명력을 지닐 수 있었다. 하지만 국내에서는 읽기이해에 관한 종단 연구가 아직 활발히 진행되지 못한 것이 현실이다. 읽기 관련 변인 탐색을 위하여 국내에서 실시한 종단연구로는 대표적으로 Kim (2013), Kim과 Kim (2015), Chung (2011), Park과 Lee (2018)의 연구 가 있다. 그러나 이 연구들은 빠른 이름대기와 같은 음운처리적 요 소들만을 독립변인으로 설정하거나(Kim, 2013), 다양한 변인들이 학년에 걸쳐 보이는 추이를 탐색하지 않았다는 점에서(Chung, 2011; Park \& Lee, 2018) 아쉬움이 있다. Manis, Seidenberg와 Doi (1999) 의 연구에서는 빠른이름대기가 종단연구 결과 이후의 이해기술에 거의 영향을 미치지 않은 것으로 나타났으며, Parrila, Kirby와 McQuarrie (2004)도 음운기술과 읽기이해와의 연관성에 대하여 다소 회의적인 결과를 보고한 바 있기 때문이다.

본 연구는 선행연구들의 논의에 기초하여 읽기이해를 측정하는 두 가지 서로 다른 형식의 검사 과제를 적용하였고, 단어재인과 어 휘뿐 아니라 읽기유창성과 형태인식을 독립변인으로 설정하여 다 음과 같은 연구문제를 탐색하고자 하였다. 먼저 (1) 저학년 시기의 어떤 변인이 중학년의 읽기이해를 유의하게 예측하는지 분석하고, (2) 저학년과 중학년 시기의 어떤 변인이 각각 동일 학년 내에서 읽 
기이해를 유의하게 설명하는지 분석함으로써 동일한 아동의 학년 이 증가함에 따라 관련 변인의 추이가 어떻게 변화하는지 파악하 고자 하였다. 읽기이해검사는 형식이 다른 두 검사를 사용하여 별 도로 분석을 진행하였고 검사에 따라 읽기이해를 설명하는 관련 변인에 어떠한 차이가 있는지 함께 확인하고자 하였다.

\section{연구방법}

\section{연구대상}

Chall (1983)은 1, 2학년 시기를 초보적인 독자의 단계로, 3, 4 학년 은 '학습을 위한 읽기’를 경험하고 읽기자료에서 정보를 얻고 지식 을 축적하기 시작하는 향상된 단계로 설명한 바 있다. 이에 근거하 여 본 연구는 광주광역시 소재 초등학교에 재학 중인 1학년과 2학 년 아동을 저학년으로 분류하여 첫 번째 검사를 실시하였고, 두 번 째 검사는 2 년 후 동일한 아동들이 각각 초등 3 학년과 4 학년, 즉 중 학년에 진입한 시기에 진행하였다. 본 연구에서는 (1) 학부모 및 교 사로부터 특수교육서비스를 받고 있지 않으며 감각적, 정서적, 청각 적 및 신경학적 문제가 없다고 확인되었고, (2) 인지적인 능력을 통 제하기 위하여 한국비언어지능검사(C-TONI-2; Park, 2014)를 실시 한 결과 지능지수가 80 을 초과한 아동을 연구대상에 포함하였다.
그 결과 첫 번째 검사 시 접촉한 39 명의 아동 중 2 명이 위의 기준에 적합하지 않았고 4 명은 개인적인 사유로 검사를 완료하지 못하여 분석대상에서 제외되었다. 두 번째 검사 시에는 첫 번째 검사 대상 이었던 33 명의 아동 중 1 명이 전학을 하여 최종적으로 분석대상으 로 선정된 아동은 1학년(두 번째 검사 시 3학년) 17 명, 2학년(두 번 째 검사 시 4학년) 15 명 총 32 명(남아 14 명, 여아 18 명)이었다. 학년 별 학생수, 연령, 지능 및 관련 변인의 검사에 관한 전반적인 기술통 계 결과는 Table 1 에 제시하였다.

\section{검사도구}

\section{준거변인}

본 연구의 준거변인(종속변인)인 읽기이해는 검사유형에 따른 변 인 간의 예측력의 차이를 탐색한 관련 선행연구(Chung et al., 2017) 를 참고로 국내 읽기이해 평가에서 자주 사용되는 국립특수교육원 읽기기초학력검사 개정판(KNISE-BAAT; Park, Kim, Song, Jung, \& Jung, 2008)의 하위검사인 짧은글이해검사와 한국어 읽기검사 (KOLRA; Pae, Kim, Yoon, \& Jang, 2015)의 하위검사인 읽기이해검 사를 사용하여 측정하였다. KNISE-BAAT 짧은글이해검사(이하 문답식 읽기이해)는 다양한 길이의 글자료를 읽고 질문에 답하는 문답과제 형식으로 총 30 문항이며, KOLRA의 읽기이해검사(이하

Table 1. Descriptive statistics for the criterion and predictor variables ( $N=32)$

\begin{tabular}{|c|c|c|c|c|}
\hline Variable & Mean \pm SD & Min-Max & Skew & Kurt \\
\hline \multicolumn{5}{|l|}{ 1st Period: Early grades } \\
\hline Age (mo) & $89.09 \pm 6.18$ & $78.00-100.00$ & -.164 & -.807 \\
\hline Nonverbal IQ (C-TONI-2) & $98.34 \pm 10.71$ & $82.00-124.00$ & .615 & -.400 \\
\hline Reading comprehension (KNISE-BAAT) & $4.63 \pm 3.16$ & $0.00-12.00$ & .519 & -.482 \\
\hline Reading comprehension (KOLRA-RC) & $8.75 \pm 3.81$ & $0.00-18.00$ & .097 & .552 \\
\hline Vocabulary (REVT-R) & $81.16 \pm 13.89$ & $55.00-105.00$ & .265 & -1.084 \\
\hline Word recognition (KOLRA-D) & $53.63 \pm 10.92$ & $12.00-69.00$ & -1.769 & 5.632 \\
\hline Reading fluency (KOLRA-RF) & $27.25 \pm 7.51$ & $8.00-44.00$ & -.333 & .721 \\
\hline Morphological awareness & $21.56 \pm 8.19$ & $4.00-32.00$ & -.647 & -.628 \\
\hline \multicolumn{5}{|l|}{ 2nd Period: Intermediate grades } \\
\hline Age (mo) & $112.60 \pm 6.03$ & $102.00-124.00$ & -.094 & -.886 \\
\hline Nonverbal IQ (C-TONI-2) & $105.00 \pm 13.02$ & $82.00-133.00$ & .513 & -.0215 \\
\hline Reading comprehension (KNISE-BAAT) & $11.38 \pm 4.61$ & $4.00-19.00$ & .206 & -.850 \\
\hline Reading comprehension (KOLRA) & $13.91 \pm 4.03$ & $1.00-22.00$ & -.749 & 2.220 \\
\hline Vocabulary (REVT-R) & $105.22 \pm 27.32$ & $11.00-174.00$ & -.759 & 4.593 \\
\hline Word recognition (KOLRA-D) & $63.03 \pm 6.34$ & $48.00-71.00$ & -.807 & -.225 \\
\hline Reading fluency (KOLRA-RF) & $39.88 \pm 10.50$ & $2.00-65.00$ & -1.171 & 4.994 \\
\hline Morphological awareness & $31.19 \pm 4.30$ & $16.00-37.00$ & -1.722 & 4.609 \\
\hline
\end{tabular}

All reported sores are raw scores except for nonverbal IO scores.

Early grades $=1 \mathrm{st}$ and 2 nd grade; Intermediate grades $=3 \mathrm{rd}$ and 4 th grade .

C-TONI-2=Korean Comprehensive Test of Nonverbal Intelligence-second edition (Park, 2014); KNISE-BAAT=Korea Institute for Special Education Basic Academic Achievement Test (Park, Kim, Song, Jung, \& Jung, 2008); REVT-R=Receptive \& Expressive Vocabulary Test-Receptive (Kim, Hong, Kim, Jang, \& Lee, 2009); KOLRA-RC=Korea Language-based Reading Assessment-Reading Comprehension (Pae, Kim, Yoon, \& Jang, 2015); D=decoding subtest; RF= passage reading fluency subtest. 
빈칸채우기식 읽기이해)는 문장 및 짧은 문단 글을 읽고 빈칸을 채 우는 과제형식으로 총 24 개 문항으로 다르게 구성되어 있다.

\section{예측변인}

예측변인(독립변인)은 국내외 선행연구에 근거하여 어휘, 단어재 인, 읽기유창성, 형태인식으로 선정하였다. 대상 아동의 어휘력 측 정에는 수용·표현어휘력검사(REVT; Kim, Hong, Kim, Jang, \& Lee, 2009)의 수용어휘력검사를 사용하였다. 단어재인에는 KOLRA 에 포함된 하위검사 중 총 80 개의 의미 및 무의미 2 음절 단어를 읽 는 해독검사를 사용하였다. 이 검사는 자소-음소 일치형 단어와 불 일치형 단어가 각각 40 개씩으로 동일하게 구성되어 있으며, 해독 시 적용해야 하는 다양한 음운변동규칙을 포함하고 있다. 읽기유 창성검사로 사용한 KOLRA의 문단글 읽기유창성검사는 아동에 게 일련의 설명글을 읽도록 한 후 정확하게 읽은 음절수를 계산하 는 방식으로 진행된다. 즉, 아동이 읽은 총 음절수에서 오류를 보인 음절의 수를 제한 후 총 소요시간으로 나누고 10 을 곱함으로써 10 초 동안 오류 없이 읽은 음절수 계산을 하게 된다.

형태인식은 국외 선행연구를 바탕으로 Chung (2016)이 제작하 여 사용한 파생어 형태인식검사 중 유추와 변환검사 두 가지를 선 정하여 측정하였다. 유추검사는 $\mathrm{A}: \mathrm{B}: \mathrm{A}^{\prime} \mathrm{B}$ ' 형식으로 '물건을 팔다: 팔기'와 같이 제시된 문항을 보고 '가방을 놓다: '에 '놓 기'라는 파생어를 유추하여 표현하도록 유도하는 방식의 검사이다 (Casalis, Deacon, \& Pacton, 2011; Deacon \& Kirby, 2004; Tong et al., 2011). 변환검사는 제시된 단어를 문장에 맞게 조작하여 변형 하는 과제로 '접다/미술시간에 종이____를 했다'를 읽고 '접기'라 는 파생어로 변환하는 방식의 문항으로 구성된다(Apel \& Lawrence, 2011; Berninger, Abbott, Nagy, \& Carlisle, 2010). 형태인식검 사는 유추검사 14 문항, 변환검사 14 문항으로 총 28 문항이며, 아동 의 읽기 수준을 고려하여 모든 문항은 음성으로 녹음하여 읽기자 료와 함께 노트북으로 제시하였다. 검사의 문항내적일관성 신뢰도 는.904로 보고되었다.

\section{검사절차}

종단연구를 위한 첫 번째와 두 번째 검사는 모두 참여 초등학교 와 $\mathrm{MOU}$ 를 맺은 후각 검사 시기가 해당된 연도의 교육과정상학기 말인 7월에 학교에 방문하여 실시하였다. 초등학교에서 제공한 도 서관, 과학실, 방과후교실, 영어센터 등의 조용하고 분리된 장소에 서 일대일 검사의 과정으로 진행하였으며 검사 후 스티커와 문구를 아동에게 선물로 제공하였다. 모든 검사는 연구자와 검사실시 및 해석에 관하여 충분한 교육을 받은 언어치료학과 대학원 석사 및
박사과정 재학생이 진행하였다. 연구보조원들은 교육 후 수차례에 걸쳐 짝지어 검사도구를 실습하였고, 검사의 신뢰도를 높이기 위해 연구보조원당 한두 가지 검사만을 지속적으로 실시하도록 배치하 였다. 전체 검사시간은 아동당 약 한 시간에서 한 시간 반 정도 소요 되었으며, 검사 순서는 무선적으로 배치하였다.

\section{통계처리}

본 연구에서는 먼저 각 학년별로 검사결과의 분포를 확인하기 위 해 기술통계치(최솟값, 최댓값, 평균, 표준편차, 왜도)를 산출하였 으며, 변인 간 상관관계를 분석하는 피어슨 적률상관계수를 실시 하였다. 또한 두 번째 검사 시기(중학년 시기)의 두 가지 읽기이해 검 사점수를 종속변인으로 하고 이를 예측하는 변인을 탐색하기 위해 첫 번째 검사의 어휘, 단어재인, 읽기유창성, 형태인식을 독립변인 으로 설정한 단계적 다중회귀분석(stepwise multiple regression analysis)을 실시하였다. 마지막으로 첫 번째와 두 번째 검사 시기별 로 각각 해당 학년의 읽기이해 점수를 예측하는 변인을 탐색하는 단계적 다중회귀분석을 실시하였다. 또한 다중공선성의 문제를 확 인하기 위한 변인 간의 분산팽창계수(variance inflation factor, $\mathrm{VIF}$ )와 회귀모형의 안정성을 확인하는 Durbin-Watson 값을 구하 였다. VIF는 1 에 근접할 때 다중공선성이 낮은 것으로 확인되며, 10 이상인 경우에는 회귀계수의 불안정성을 함의한다. Durbin-Watson 값은 2에 근접할수록 잔차 간의 상관계수가 낮아 적합한 회귀 모형인 것으로 나타나므로 각 계수를 확인하는 것이 필요하다고 판단되었다. 모든 통계처리에는 IBM SPSS version 23 (IBM, Armonk, NY, USA)이 사용되었다.

\section{연구결과}

\section{읽기이해 및 관련 변인의 기술통계와 상관관계}

본 연구에서 저학년과 중학년 시기에 실시한 읽기이해 및 관련 변인의 점수에 관한 기술통계 결과와 상관계수 분석결과를 Tables 1 과 2에 제시하였다. 준거변인인 두 읽기이해검사와 예측변인의 평 균, 표준편차, 최솟값, 최댓값 및 왜도를 산출하였다. 왜도는 모두 - 2 에서 +2 사이에 해당하여 적은 학생수에도 불구하고 대부분의 변 인들이 대칭적 정규분포를 보인 것으로 나타났다. 첨도는 저학년의 단어재인, 중학년의 어휘, 읽기유창성, 형태인식을 제외한 나머지 변인에서 고르게 분포되어 있음을 알 수 있었다. 상관계수 분석 시 에는 연구문제에 따라 먼저 두 번째 검사 시기인 중학년의 읽기이 해와 저학년 시기의 변인들 간의 상관관계를 구하였고, 각 학년 내 변인 간의 상관을 알아보기 위해 중학년 시기의 상관관계 분석결 
Table 2. Correlations among the criterion and predictor variables

\begin{tabular}{|c|c|c|c|c|c|c|c|c|}
\hline & Variables & 1 & 2 & 3 & 4 & 5 & 6 & 7 \\
\hline \multirow{2}{*}{$\begin{array}{l}\text { 2nd Period: Intermediate } \\
\text { grade }\end{array}$} & 1. Reading comprehension (KNISE-BAAT) & 1 & & & & & & \\
\hline & 2. Reading comprehension (KOLRA-RC) & $.633^{* *}$ & 1 & & & & & \\
\hline \multirow[t]{6}{*}{ 1st Period: Early grades } & 3. Reading comprehension (KNISE-BAAT) & $.586^{* *}$ & $.611^{* *}$ & 1 & & & & \\
\hline & 4. Reading comprehension (KOLRA-RC) & $.544^{* *}$ & $.621^{* *}$ & $.598^{* *}$ & 1 & & & \\
\hline & 5. Vocabulary (REVT-R) & .300 & .276 & .252 & .026 & 1 & & \\
\hline & 6. Word recognition (KOLRA-D) & .279 & $.681^{* *}$ & $.514^{* *}$ & $.572^{* *}$ & .029 & 1 & \\
\hline & 7. Reading fluency (KOLRA-RF) & .310 & $.616^{* *}$ & $.451^{* *}$ & $.592^{* *}$ & .101 & $.835^{* *}$ & 1 \\
\hline & 8. Morphological awareness & $.560^{* *}$ & $.442^{*}$ & $.474^{* *}$ & .184 & $.363^{*}$ & .309 & $.386^{*}$ \\
\hline \multirow{6}{*}{$\begin{array}{l}\text { 2nd Period: Intermediate } \\
\text { grades }\end{array}$} & 1. Reading comprehension (KNISE-BAAT) & 1 & & & & & & \\
\hline & 2. Reading comprehension (KOLRA) & $.633^{* *}$ & 1 & & & & & \\
\hline & 3. Vocabulary (REVT-R) & .237 & .322 & 1 & & & & \\
\hline & 4. Word recognition (KOLRA-D) & .226 & $.397^{*}$ & .023 & 1 & & & \\
\hline & 5. Reading fluency (KOLRA-RF) & $.492^{* *}$ & $.746^{* *}$ & .298 & $.486^{* *}$ & 1 & & \\
\hline & 6. Morphological awareness & .237 & $.372^{*}$ & .347 & $.359^{*}$ & $.452^{*}$ & 1 & \\
\hline
\end{tabular}

KNISE-BAAT = Korea Institute for Special Education Basic Academic Achievement Test (Park, Kim, Song, Jung, \& Jung, 2008); REVT-R=Receptive \& Expressive Vocabulary Test-Receptive (Kim, Hong, Kim, Jang, \& Lee, 2009); KOLRA-RC=Korea Language-based Reading Assessment-Reading Comprehension (Pae, Kim, Yoon, \& Jang, 2015); $\mathrm{D}=$ decoding subtest; $\mathrm{RF}=$ passage reading fluency subtest.

${ }^{*} p<.05,{ }^{* *} p<.01$.

Table 3. Summary of stepwise multiple regression analyses showing predictors in 1st period to reading comprehension in 2nd period

\begin{tabular}{|c|c|c|c|c|c|c|}
\hline Steps and variables & B & $\beta$ & $\mathrm{R}^{2}$ & Adj. $R^{2}$ & $\Delta \mathrm{R}^{2}$ & $F$ \\
\hline \multicolumn{7}{|l|}{ 1st Period Reading comprehension (KNISE-BAAT) } \\
\hline 1. Reading comprehension (KNISE-BAAT) & .855 & .586 & .344 & .408 & .344 & $15.717^{* * *}$ \\
\hline 2. Reading comprehension (KNISE-BAAT) & .603 & .414 & .446 & .408 & .103 & $5.372 .^{*}$ \\
\hline Morphological awareness & .204 & .364 & & & & \\
\hline \multicolumn{7}{|l|}{ 2nd Period Reading Comprehension (KOLRA) } \\
\hline 1. Word recognition & .251 & .681 & .464 & .446 & .464 & $25.936^{* * *}$ \\
\hline 2. Word recognition & .179 & .484 & .543 & .512 & .080 & $5.054^{*}$ \\
\hline Reading comprehension (KOLRA) & .363 & .344 & & & & \\
\hline 3. Word recognition & .177 & .479 & .608 & .566 & .064 & $4.589^{*}$ \\
\hline Reading comprehension (KOLRA) & .359 & .340 & & & & \\
\hline Vocabulary & .074 & .254 & & & & \\
\hline
\end{tabular}

KNISE-BAAT = Korea Institute for Special Education Basic Academic Achievement Test (Park, Kim, Song, Jung, \& Jung, 2008); REVT-R=Receptive \& Expressive Vocabulary Test-Receptive (Kim, Hong, Kim, Jang, \& Lee, 2009); KOLRA-RC=Korea Language-based Reading Assessment-Reading Comprehension (Pae, Kim, Yoon, \& Jang, 2015); D= decoding subtest; $\mathrm{RF}=$ passage reading fluency subtest.

${ }^{*} p<.05,{ }^{* * *} p<.001$.

과를 추가하였다.

\section{중학년 시기의 읽기이해에 대한 저학년 시기의 예측변인}

중학년 시기의 읽기이해능력을 가장 잘 예측하는 저학년의 변인 은 무엇인지 확인하기 위하여 저학년의 어휘, 단어재인, 읽기유창 성, 형태인식을 예측변인으로 설정하고, 문답식 읽기이해검사와 빈 칸채우기식 읽기이해검사를 각각 준거변인으로 설정한 단계적 다 중회귀분석을 실시하였다. 본 회귀모형의 VIF는 두 가지 다른 형식 의 읽기이해검사에 관한 모형에서 각각 1.290 과 1.001 로 1 에 근접하
여 회귀분석의 오류 가능성을 의미하는 다중공선성이 없는 것으 로 해석되었다. Durbin-Watson 또한 2.287과 2.194로 2에 가까운 값으로 나타나 본 연구의 회귀모형이 적합한 것으로 판단되었다.

중학년 시기의 읽기이해에 대한 저학년 시기 변인들의 예측력에 관한 회귀분석 결과는 Table 3에 제시하였다. 먼저, 중학년 시기의 문답식 읽기이해를 가장 유의하게 예측하는 저학년 시기의 변인은 문답식 읽기이해와 형태인식으로 나타났다. 즉, 중학년 시기 읽기이 해 총 변화량의 $45 \%$ (수정 결정계수에 의하면 $41 \%$ )가 저학년 시기 의 읽기이해와 형태인식에 의해 설명되며, 표준화 계수에 의한 순서 
Table 4. Summary of stepwise multiple regression analyses showing predictors to reading comprehension in each period

\begin{tabular}{|c|c|c|c|c|c|c|c|}
\hline Period & Steps and variables & B & $\beta$ & $\mathrm{R}^{2}$ & Adj. $R^{2}$ & $\Delta R^{2}$ & $F$ \\
\hline \multirow{6}{*}{$\begin{array}{l}\text { 1st Period: } \\
\text { Early grades }\end{array}$} & Reading comprehension (KNISE-BAAT) & & & & & & \\
\hline & 1. Word recognition & .149 & .514 & .264 & .240 & .264 & $10.769^{* *}$ \\
\hline & 2. Word recognition & .118 & .406 & .374 & .331 & .110 & $5.107^{*}$ \\
\hline & Morphological awareness & .135 & .349 & & & & \\
\hline & Reading comprehension (KOLRA) & & & & & & \\
\hline & 1. Reading fluency & .300 & .592 & .350 & .328 & .350 & $16.154^{* * *}$ \\
\hline \multirow{4}{*}{$\begin{array}{l}\text { 2nd Period: } \\
\text { Intermediate grades }\end{array}$} & Reading comprehension (KNISE-BAAT) & & & & & & \\
\hline & 1. Reading fluency & .216 & .492 & .242 & .217 & .242 & $9.573^{* *}$ \\
\hline & Reading comprehension (KOLRA) & & & & & & \\
\hline & 1. Reading fluency & .286 & .746 & .557 & .542 & .557 & $37.738^{* * *}$ \\
\hline
\end{tabular}

KNISE-BAAT = Korea Institute for Special Education Basic Academic Achievement Test (Park, Kim, Song, Jung, \& Jung, 2008); KOLRA=Korea Language-based Reading Assessment (Pae, Kim, Yoon, \& Jang, 2015).

${ }^{*} p<.05,{ }^{* *} p<.01,{ }^{* * *} p<.001$.

는 문답식 읽기이해 $(\beta=.414)$ 와 형태인식 $(\beta=.364)$ 의 순서인 것으 로 파악되었다. 두 번째로, 빈칸채우기식 읽기이해를 가장 유의하 게 예측하는 저학년 시기의 변인은 문답식 읽기이해를 예측하는 변 인들과 달리 단어재인, 빈칸채우기 형식의 읽기이해, 어휘인 것으 로 분석되었다. 이 변인들은 중학년 시기 해당 읽기이해 총 변화량 의 $61 \%$ (수정 결정계수에 의하면 57\%)를 설명하며, 표준화 계수에 의한 순서는 단어재인 $(\beta=.479)$, 읽기이해( $\beta=.340)$, 어휘( $\beta=.254)$ 인 것으로 나타났다.

\section{저학년과 중학년 시기 내 읽기이해에 대한 설명변인}

본 연구에서는 동일 학년집단 내에 읽기이해에 관한 설명변인이 무엇인지를 추가적으로 탐색하고자 각 검사 시기별로 단계적 중다 회귀분석을 실시하였다. 이는 학년별로 다른 아동을 대상으로 실 시하는 횡단연구방식과는 달리 동일한 아동이 저학년에서 중학년 으로 진입하였을 때 각 학년시기에 읽기이해를 설명하는 변인의 추 이가 달라지는지 그리고 그 변화는 어떠한지 확인하고자 함이었다. 본 회귀모형의 VIF는 모두 1.000-1.105로 1에 근접하여 회귀분석의 오류 가능성을 의미하는 다중공선성이 없는 것으로 해석되었다. Durbin-Watson 또한 1.408-2.504로 잔차 간의 상관관계가 없이 2 에 가까운 값으로 나타나 본 연구의 회귀모형이 적합한 것으로 판 단되었다. 단계적 회귀분석 결과 저학년 시기의 문답식 읽기이해와 가장 유의하게 관련된 동일 시기의 변인은 단어재인( $\beta=.406)$ 과 형 태인식( $\beta=.349$ )의 순서로 총 변화량의 37\% (수정 결정계수 $33 \%$ ) 를 설명하는 것으로 나타났다. 또한 저학년 시기의 빈칸채우기식 읽기이해를 설명하는 동일 시기의 변인은 읽기유창성 $(\beta=.592)$ 으 로 총 변화량의 $35 \%$ (수정 결정계수 $33 \%$ )가 해당 변인에 의해 설명 되는 것으로 분석되었다. 흥미롭게도 중학년 시기의 문답식 읽기이
해와 빈칸채우기식 읽기이해를 유의하게 설명하는 동일 시기의 변 인도 모두 유일하게 읽기유창성인 것으로 분석되었다(각 $\beta=.492$, $\beta=.746)$. 두 형식의 읽기이해는 읽기유창성 변인에 의해 각각 $24 \%$ (수정 결정계수 22\%), 56\% (수정 결정계수 54\%) 설명되는 것으로 나타났다. 검사 시기별 집단 내 중다회귀분석 결과는 Table 4에 제 시하였다.

\section{논의 및 결론}

본 연구에서는 초등학교 1학년과 2학년 아동 32 명을 대상으로 읽기이해 및 예측변인에 관한 검사를 실시한 뒤 2년 후 동일 아동 들이 3 학년과 4 학년에 진입한 시기에 재검사를 실시하여 종단적 연 구방식에 기반한 변인 간의 인과적 경향성을 분석하고자 하였다. 검사의 내용과 유형에 따라 측정 구인이 다르기 때문에 읽기이해 를 예측하는 변인에도 차이가 있었음을 보고한 선행연구들(Chung et al., 2017; Cutting \& Scarborough, 2006)을 근거로 준거변인인 읽 기이해 검사 시 국내에서 대표적인 두 검사도구를 사용하였다. 또 한 단어재인 및 언어관련 요소뿐 아니라 읽기유창성과 형태인식의 예측력을 보고하는 연구결과들이 점차 증가함에 따라 이들 변인 을 예측변인으로 선정하였다.

연구결과에 의하면 중학년 시기의 문답식 읽기이해(KNISE-BA$\mathrm{AT}$ 짧은글이해)를 예측하는 저학년 시기의 변인은 동일 형식 읽기 이해와 형태인식으로 나타났다. 반면 검사의 형식이 다른 중학년 시기의 빈칸채우기식 읽기이해(KOLRA 읽기이해)를 유의하게 예 측하는 저학년 시기의 변인은 단어재인, 동일 형식 읽기이해, 어휘 의 순서로 나타났다. 본 연구결과와 같이 초기의 읽기이해기술이 후기의 읽기이해를 강하게 예측하는 주요하고 고유한 변인임은 
Oakhill과 Cain (2007), Perfetti 등(2005)도 꾸준히 보고한 바 있다. 따라서 논의에서는 두 형식의 읽기이해를 각각 예측하는 추가적인 변인에 초점을 맞추고자 하였다.

먼저, 본 연구와 마찬가지로 서로 다른 읽기이해검사들의 예측변 인을 비교한 Cutting과 Scarborough (2006)는 빈칸 채우기 형식의 읽기이해검사를 사용한 경우 단어재인이 $11.9 \%$ 로 가장 큰 영향력 을 보였으며, 문답식 읽기이해검사 결과( $6.1 \%, 7.5 \%)$ 와 비교할 때 영 향력이 두 배까지 차이를 보이는 것으로 보고하였다. 본 연구에서 도 중학년의 빈칸채우기식 읽기이해검사에 대하여 단어재인과 어 휘 변인의 순서로 유의한 예측력을 보여 저학년 시기에 음가에 맞 게 정확히 단어를 해독하는 능력이 이후의 읽기이해를 가장 크게 설명하는 것으로 분석되었다. 이는 해당 형식의 읽기이해검사가 문 장 수준의 글을 읽고 빈칸에 적절한 형태소를 기억에서 인출하여 (어휘력) 정확하게 채우는(단어쓰기) 능력을 기반으로 하기 때문일 것이다. 더우기 빈칸채우기식 읽기이해검사는 맥락 단서에 의존하 여 의미를 추론하는 능력보다는 문장 내 단어를 정확하게 해독하 는 능력이 좀 더 요구되는 검사이기도 하다. 반면, 짧은 글을 읽고 질문에 답하거나 선다형 답을 선택하는 문답형식의 읽기이해검사 에 대한 중학년 시기의 능력에는 저학년 시기의 형태인식이 더 높 은 예측력을 보였다. 여기에서 형태인식이 짧은 문장을 읽고 빈칸 에 적절한 어휘나 문법형태소를 채워 넣는 빈칸채우기식 읽기이해 검사 결과를 예측하지 않고, 긴 텍스트를 읽고 문단 내 정보를 유추 하거나 추론 질문에 대답하기 위해 선다형 답을 선택해야 하는 문 답식 읽기이해검사를 유의하게 예측한다는 점은 흥미로운 부분이 다. 이는 형태인식기술이 형태소 구조에 대한 의식적 인식과 조작 을 요구하는 메타언어능력일 뿐 아니라, 본 연구에서 사용한 형태 인식검사의 내용이 파생어 간의 관계와 형성 규칙을 유추하도록 유 도하는 과제로서 문답형식 읽기이해과제의 유추적인 특성과 유사 한 데에 기인한 결과일 수 있다. Manolitsis, Grigorakis와 Georgiou (2017)가 실시한 종단연구에서도 유치원과 1,2 학년 초기의 자모지 식, 음운인식, 빠른이름대기, 어휘지식 등을 함께 분석하였으나 형 태인식이 후기의 읽기이해를 가장 잘 예측하는 중요한 변인으로 나 타났다. 특히 형태인식은 복합어나 파생어 혹은 형태적으로 복잡 한 어미변화를 인식하여 그 의미를 파악하도록 돕기에 어휘의 질적 증가에 유의하게 관련된 변인으로 밝혀지고 있으며(Chung, 2016; Kieffer \& Lesaux, 2012; Sparks \& Deacon, 2015), 어휘력을 매개로 하여 읽기이해에 직간접적으로 영향을 미치기도 한다(Apel, Brimo, Diehm, \& Apel, 2013; Gibson \& Wolter, 2015). 따라서 저학년 시기 의 단어 읽기, 형태인식 및 어휘능력이 중학년의 읽기이해 변량을 유의하게 예측한다는 본 연구결과는 읽기능력 증진을 위한 조기
읽기 프로그램 구성에 시사하는 바가 크다. 즉 정확한 단어 읽기를 가르치고자 할 때 아동이 단어 내 형태소 구조를 인식하고 활용할 수 있도록 함께 지도함으로써 복잡한 어휘의 의미를 쉽게 이해하고 생성하는 능력을 증진시킬 수 있기 때문이다.

두 번째로 저학년과 중학년 각 시기 내에 동일 아동의 읽기이해 변량을 유의하게 설명하는 변인에 변화된 추이가 존재하는지 추가 로 탐색하고자 하였다. 그 결과 저학년 시기에 문답식 읽기이해를 유의하게 설명하는 변인은 단어재인과 형태인식이었고, 빈칸채우 기 읽기이해에서는 읽기유창성이 가장 주요하고 고유한 설명변인 으로 나타났다. 본 연구에서는 학년이 바뀜에 따라 설명변인의 추 이가 변화를 보일 것이라고 기대하였으나 중학년 시기에도 읽기이 해검사의 유형에 상관없이 두 검사에서 모두 읽기유창성이 유의한 설명변인으로 분석되었다. 이러한 결과는 초등 저학년의 경우 단어 재인과 읽기유창성이 더 높은 관련성을 지니고, 초등 고학년의 경 우 읽기유창성과 읽기이해가 증가된 관련성을 지닌다는 Kim 등 (2016)의 보고나 초등 저학년과 중학년에서 모두 읽기유창성이 읽 기이해를 더 잘 설명하는 요인으로 나타난 Yoon (2016)의 연구결과 와 매우 유사하다. 저학년 시기에 단어재인의 영향력이 뚜렷하고 일관되게 보고되었던 국외연구 결과에 비해 국내연구에서 읽기유 창성의 전반적인 설명력이 이처럼 더 우세한 것은 표층표기체계를 지닌 한국어의 특성상 단어수준 읽기의 습득 속도가 더 빠르고 용 이하기 때문일 수 있다. 개별 단어나 문장을 정확히 해독하는 기술 을 더 이른 시기에 숙달한다는 것은 저학년 시기부터 제시되는 글 을 빠르고 정확하고, 효율적으로 읽을 수 있게 된다는 것을 의미하 며, 복잡한 단어나 글 전체의 의미를 이해하기 위한 인지적 자원을 더 많이 보유할 수 있음을 함의한다. 본 연구의 결과를 살펴보면 종 단분석에서는 초기의 읽기유창성이 이후의 읽기이해에 대한 예측 변량을 지니지 않았으며, 오히려 횡단적으로 동일시기에 측정된 읽 기이해능력만을 강력하게 설명하는 것으로 나타났다. 이러한 패턴 이 의미하는 바는 무엇인가? 본 연구에서는 문단글 읽기유창성이 '현재진행형' 인지처리 과정에 기반한 요소로서 기능하기 때문이 아닌가 추론하고자 한다. 정확하고 빠른 읽기유창성능력은 글에 대한 기억, 이해, 추론을 위한 과정이 원활히 진행되도록 일정 정도 인지적 자원을 동시에 지원하는 역할을 하기 때문이다(Klauda \& Guthrie, 2008). 이처럼 읽기유창성의 역할과 영향력에 대한 관심 이 증가하면서 최근 연구들은 단어재인, 언어, 읽기이해로 구성된 읽기의 단순모델 관점에서 벗어나 읽기유창성도 별개의 요인으로 고려해야 한다고 주장하기도 하였다(Kim et al., 2016; Manolitsis et al., 2017; Silverman, Speece, Harring, \& Ritchey, 2013). 이러한 논 의와 본 연구의 결과는 이후 읽기유창성과 읽기이해의 관련성 및 
읽기유창성을 분석하는 좀 더 상세한 기준 및 예측변인에 관한 연 구의 필요성을 함의한다. 아울러 본 연구가 종단연구의 방식으로 후기 읽기이해를 예측하는 초기 변인들을 탐색하였으나 대상 아동 의 수가 제한적이기에 일반화에 주의가 필요하다. 추후 대상 아동 의 충분한 수만이 아니라 다양한 장애군을 대상으로 종단적인 후 속연구가 진행된다면 평가 및 중재를 위해 유용한 방향과 근거를 제시할 수 있을 것이라 사료된다.

\section{REFERENCES}

Apel, K., Brimo, D., Diehm, E., \& Apel, L. (2013). Morphological awareness intervention with kindergartners and first-and second-grade students from low socioeconomic status homes: a feasibility study. Language, Speech, and Hearing Services in Schools, 44(2), 161-173.

Apel, K., \& Lawrence, J. (2011). Contributions of morphological awareness skills to word-level reading and spelling in first-grade children with and without speech sound disorder. Journal of Speech, Language, and Hearing Research, 54(4), 1312-1327.

Berninger, V. W., Abbott, R. D., Nagy, W., \& Carlisle, J. (2010). Growth in phonological, orthographic, and morphological awareness in grades 1 to 6 . Journal of Psycholinguistic Research, 39(2), 141-163.

Bowers, P. N., \& Kirby, J. R. (2010). Effects of morphological instruction on vocabulary acquisition. Reading and Writing, 23(5), 515-537.

Cain, K., Oakhill, J., \& Bryant, P. (2004). Children's reading comprehension ability: concurrent prediction by working memory, verbal ability, and component skills. Journal of Educational Psychology, 96(1), 31-42.

Carlisle, J. F. (1995). Morphological awareness and early reading achievement. In L. B. Feldman (Ed.), Morphological aspects of language processing (pp. 189-209). Hillsdale, NJ: Erlbaum.

Casalis, S., Deacon, S. H., \& Pacton, S. (2011). How specific is the connection between morphological awareness and spelling? A study of French children. Applied Psycholinguistics, 32(3), 499-511.

Catts, H. W., \& Kamhi, A. G. (2005). The connections between language and reading disabilities. Mahwah, NJ: Lawrence Erlbaum Associates.

Chall, J. (1983). Stages of reading development. New York, NY: McGraw-Hill.

Chung, B. J. (2011). Relationships among word recognition, reading comprehension, phonological awareness, working memory, listening comprehension, and inferential skills: a two-year longitudinal study of second and third graders. Journal of Speech \& Hearing Disorders, 20(1), 103-121.

Chung, B. J. (2016). Morphological awareness on derivational affixes and relat- ed variables in school-aged children (Doctoral dissertation). Ewha Womans University, Seoul, Korea.

Chung, B. J., Kim, Y. T., \& Yoon, H. J. (2017). Relative contributions of components to different reading comprehension tasks in grade 3-4. Communication Sciences \& Disorders, 22(1), 66-75.

Cutting, L. E., \& Scarborough, H. S. (2006). Prediction of reading comprehension: relative contributions of word recognition, language proficiency, and other cognitive skills can depend on how comprehension is measured. Scientific Studies of Reading, 10(3), 277-299.

Deacon, S. H., Kieffer, M. J., \& Laroche, A. (2014). The relation between morphological awareness and reading comprehension: evidence from mediation and longitudinal models. Scientific Studies of Reading, 18(6), 432-451.

Deacon, S. H., \& Kirby, J. R. (2004). Morphological awareness: Just "more phonological"? The roles of morphological and phonological awareness in reading development. Applied Psycholinguistics, 25(2), 223-238.

Fuchs, L. S., Fuchs, D., Hosp, M. K., \& Jenkins, J. R. (2001). Oral reading fluency as an indicator of reading competence: a theoretical, empirical, and historical analysis. Scientific Studies of Reading, 5(3), 239-256.

Gibson, F. E., \& Wolter, J. A. (2015). Morphological awareness intervention to improve vocabulary and reading success. Perspectives on Language Learning and Education, 22(4), 147-155.

Hoover, W. A., \& Gough, P. B. (1990). The simple view of reading. Reading and Writing, 2(2), 127-160.

Keenan, J. M., Betjemann, R. S., \& Olson, R. K. (2008). Reading comprehension tests vary in the skills they assess: differential dependence on decoding and oral comprehension. Scientific Studies of Reading, 12(3), 281-300.

Kieffer, M. J., \& Lesaux, N. K. (2012). Development of morphological awareness and vocabulary knowledge in Spanish-speaking language minority learners: a parallel process latent growth curve model. Applied Psycholinguistics, 33(1), 23-54.

Kim, A. H. (2013). Prediction of reading comprehension of elementary students: a 20-month longitudinal study. Communication Sciences \& Disorders, $18(3), 258-268$.

Kim, A. H., \& Kim, U. J. (2015). A longitudinal study on prediction of word recognition, reading fluency, and reading comprehension of 4-year-old children. Special Education \& Rehabilitation Science, 54(4), 45-70.

Kim, A. H., Kim, U. J., \& Kang, E. Y. (2016). A confirmatory factor analysis on reading constructs across ages. Communication Sciences \& Disorders, 21(4), 631-641.

Kim, A. H., Yoo, H. S., Hwang, M., Kim, U. J., \& Koh, S. R. (2010). Prediction 
of reading comprehension in elementary school students. Korean Journal of Communication Disorders, 15(3), 357-380.

Kim, Y. S., Petscher, Y., Schatschneider, C., \& Foorman, B. (2010). Does growth rate in oral reading fluency matter in predicting reading comprehension achievement? Journal of Educational Psychology, 102(3), 652-667.

Kim, Y. T., Hong, G. H., Kim, G. H., Jang, H. S., \& Lee, J. Y. (2009). Receptive and Expressive Vocabulary Test (REVT). Seoul: Seoul Community Rehabilitation Center.

Klauda, S. L., \& Guthrie, J. T. (2008). Relationships of three components of reading fluency to reading comprehension. Journal of Educational psychology, 100(2), 310-321.

Manis, F. R., Seidenberg, M. S., \& Doi, L. M. (1999). See Dick RAN: rapid naming and the longitudinal prediction of reading subskills in first and second graders. Scientific Studies of Reading, 3(2), 129-157.

Manolitsis, G., Grigorakis, I., \& Georgiou, G. K. (2017). The longitudinal contribution of early morphological awareness skills to reading fluency and comprehension in Greek. Frontiers in Psychology, 8, 1793.

Nagy, W., Berninger, V. W., \& Abbott, R. D. (2006). Contributions of morphology beyond phonology to literacy outcomes of upper elementary and middle-school students. Journal of Educational Psychology, 98(1), 134-147.

Oakhill, J., \& Cain, K. (2007). Issues of causality in children's reading comprehension. In D. S. McNamara (Eds.), Reading comprehension strategies: theories, intervention, and technologies (pp. 47-72). Mahwah, NJ: Lawrence Erlbaum Associates.

Pae, S., Kim, M., Yoon, H. J., \& Jang, S. (2015). Korean Language based Reading Assessment (KOLRA). Seoul: Hakjisa.

Park, G., Kim, G., Song, Y., Jung, D., \& Jung, I. (2008). Korea Institute for Special Education-Basic Academic Achievement Test (KISE-BAAT). Ansan: Korea Institute for Special Education.

Park, H. (2014). Korean version of Comprehensive Test of Nonverbal Intelligence Second Edition (K-CTONI-2). Seoul: Mindpress.

Park, H., \& Lee, H. (2018). A longitudinal study of reading related skills in grade 2 as predictors of reading comprehension in grade 4 . The Journal of Humanities and Social Science, 9(4), 687-702.

Parrila, R., Kirby, J. R., \& McQuarrie, L. (2004). Articulation rate, naming speed, verbal short-term memory, and phonological awareness: longitudinal predictors of early reading development? Scientific Studies of Reading,
8(1), 3-26.

Perfetti, C. A., \& Hart, L. (2001). The lexical basis of comprehension skill. In D. S. Gorfein (Ed.), On the consequences of meaning selection: perspectives on resolving lexical ambiguity (pp. 67-86). Washington, DC: American psychological Association.

Perfetti, C. A., \& Hogaboam, T. (1975). Relationship between single word decoding and reading comprehension skill. Journal of Educational Psychology, 67(4), 461-469.

Perfetti, C. A., Landi, N., \& Oakhill, J. (2005). The acquisition of reading comprehension skill. In M. J. Snowling \& C. Hulme (Eds.), Handbook of developmental psychology (pp. 209-226). Malden, MA: Blackwell Publishing.

Silverman, R. D., Speece, D. L., Harring, J. R., \& Ritchey, K. D. (2013). Fluency has a role in the simple view of reading. Scientific Studies of Reading, 17(2), 108-133.

Sparks, E., \& Deacon, S. H. (2015). Morphological awareness and vocabulary acquisition: A longitudinal examination of their relationship in Englishspeaking children. Applied Psycholinguistics, 36(2), 299-321.

Stanovich, K. E., \& Siegel, L. S. (1994). Phenotypic performance profile of children with reading disabilities: a regression-based test of the phonological-core variable-difference model. Journal of Educational Psychology, 86(1), 24-53.

Storch, S. A., \& Whitehurst, G. J. (2002). Oral language and code-related precursors to reading: evidence from a longitudinal structural model. Developmental Psychology, 38(6), 934-947.

Tong, X., Deacon, S. H., Kirby, J. R., Cain, K., \& Parrila, R. (2011). Morphological awareness: a key to understanding poor reading comprehension in English. Journal of Educational Psychology, 103(3), 523-534.

Verhoeven, L., \& Van Leeuwe, J. (2008). Prediction of the development of reading comprehension: a longitudinal study. Applied Cognitive Psychology, 22(3), 407-423.

Yoon, H. (2015). Prediction of reading comprehension in early and late elementary grades: contribution of word decoding, vocabulary and syntactic knowledge. Communication Sciences \& Disorders, 20(4), 536-546.

Yoon, H. (2016). The role of reading accuracy and reading fluency in reading comprehension for school-aged children. Journal of Speech-Pathology \& Hearing Disorders, 25(4), 109-118. 


\section{국문초록}

\section{초등학교 저학년과 중학년의 읽기이해 관련 변인에 관한 종단연구 정부자 · 윤효진 \\ 조선대학교 보건과학대학 언어치료학과}

배경 및 목적: 종단연구방식은 변인들의 인과관계를 파악하는 데 효과적이나 국내에서 읽기이해에 초점을 맞추어 진행된 연구는 제한 적이었다. 최근 연구들은 형태인식과 읽기유창성의 영향력에 주목하고 있기에 본 연구는 저학년 시기의 단어재인, 어휘, 읽기유창성 그 리고 형태인식이 중학년 시기의 읽기이해를 얼마나 예측하는지 탐색하고자 하였다. 방법: 본 연구는 초등학교 저학년 남아 14 명, 여아 18 명 총 32 명을 대상으로 하였다. 두 가지 형식의 읽기이해와 예측변인에 관한 검사를 저학년 시기에 일차로 진행하였고, 2 년 후 아동들 이 중학년에 진입한 시점에 동일한 검사를 한 번 더 진행하였다. 변인 간의 상관계수 분석과 두 준거변인에 대한 예측변인의 설명력을 파 악하기 위해 단계적 다중회귀분석을 실시한 후 그 결과를 비교하였다. 결과: 중학년 시기의 문답 및 빈칸채우기 읽기이해를 예측하는 가장 주요한 변인은 저학년 시기의 각 형식에 따른 읽기이해였다. 다음으로 주요한 예측변인은 중학년의 문답식 읽기이해에는 저학년 시기의 형태인식, 중학년의 빈칸채우기식 읽기이해에는 저학년 시기의 단어재인과 어휘인 것으로 분석되었다. 또한 횡단적으로 저학년 과 중학년 집단 내를 분석한 결과 저학년 시기에는 단어재인과 형태인식이 문답식 읽기이해에 대한 주요 설명변인이었으며, 그 외에는 읽기유창성이 동일 학년의 읽기이해를 설명하는 주요하고 고유한 변인으로 나타났다. 논의 및 결론: 읽기이해는 다양한 구인들이 포함 되는 복잡한 인지적 과정이므로, 읽기이해검사의 형식에 따라 예측변인이 다양하게 나타났다. 동일 학년집단 내에서는 읽기유창성이 읽기이해를 강하게 설명하였는데 이는 효율적인 읽기유창성 기술이 글의 의미를 파악할 인지적 자원을 보유할 수 있도록 돕기 때문이 라고 해석되었다.

핵심어: 종단연구, 읽기이해, 단어읽기, 읽기유창성, 형태인식

본 논문은 2017학년도 조선대학교 학술연구비의 지원을 받아 연구되었음.

\section{참고문헌}

김애화(2013). 초등학생의 읽기이해성취도에 대한 예측 변인 종단 연구: 20개월 간 추적 검사를 통하여. Communication Sciences \& Disorders, 18(3), 258-268.

김애화, 김의정(2015). 만 4세 아동의 읽기 성취도에 대한 2년 종단연구. 특수교육재활과학연구, 54(4), 45-70.

김애화, 김의정, 강은영(2016) 확인적 요인분석을 활용한 연령별 읽기 구조에 대한 연구. Communication Sciences \& Disorders, 21(4), 631-641.

김애화, 유현실, 황미아, 김의정, 고성룡(2010). 초등학생의 읽기이해 능력 예측변인에 관한 연구. 언어청각장애연구, 15(3), 357-380.

김영태, 홍경훈, 김경희, 장혜성, 이주연(2009). 수용·표현어휘력검사(REVT). 서울: 서울장애인종합복지관.

박경숙, 김계옥, 송영준, 정동영, 정인숙(2008). 기초학력검사(Korea Institute for Special Education-Basic Academic Achievement Test, KISE-

BAAT). 안산: 국립특수교육원.

박현린, 이혜승(2018). 초등학교 저학년의 읽기 관련 변인이 초등학교 고학년의 읽기 이해 성취도에 미치는 종단적 영향력 검토. 인문사회21, 9(4),

687-702.

박혜원(2014). 한국 비언어지능검사 2판(K-CTONI-2). 서울: 마인드프레스.

배소영, 김미배, 윤효진, 장승민(2015). 한국어 읽기검사(KOLRA). 서울: 학지사.

윤효진(2015). 초등 저학년과 고학년의 읽기이해 예측 요인 연구. Communication Sciences \& Disorders, 20(4), 536-546.

윤효진(2016). 학령기 아동의 읽기이해 관련 요인. 언어치료연구, 25(4), 108-118.

정부자(2011). 초등학교 저학년 읽기부진아동의 읽기능력 및 읽기관련변인에 대한 종단연구. 언어치료연구, 20(1), 103-121. 
Bhu Ja Chung, et al. • Contributions to Reading

정부자(2016). 초등학교 저학년과 중학년 일반아동의 파생어 형태인식 발달 및 예측 변인 탐색. 이화여자대학교 대학원 박사학위논문.

정부자, 김영태, 윤효진(2017). 읽기이해검사의 형식에 따른 관련 요인 탐색: 초등학교 3-4학년을 대상으로. Communication Sciences \& Disorders, 22(1), 66-75.

\section{ORCID}

정부자(https://orcid.org/0000-0002-6158-6637); 윤효진(https://orcid.org/0000-0003-0011-2566) 